\title{
Delineating ground deformation over the Tengiz oil field, Kazakhstan, using the Intermittent SBAS (ISBAS) DInSAR algorithm
}

Stephen Grebby ${ }^{\mathrm{a},{ }^{*}}$, Elmira Orynbassarova ${ }^{\mathrm{b}}$, Andrew Sowter ${ }^{\mathrm{c}}$, David Gee $^{\mathrm{a}, \mathrm{c}}$, Ahmed Athab $^{\mathrm{a}, \mathrm{c}}$

a Nottingham Geospatial Institute, University of Nottingham, Innovation Park, Nottingham NG7 2TU, UK

${ }^{\mathrm{b}}$ Kazakh National Research Technical University named after K.I.Satbayev, Satbayev 22,

Almaty, Kazakhstan

${ }^{c}$ Geomatic Ventures Limited, Nottingham Geospatial Building, Triumph Road, Nottingham NG7 2TU, UK

* Corresponding author. Tel: +44 (0)1159513883

E-mail address: stephen.grebby@nottingham.ac.uk

Keywords: InSAR; Intermittent SBAS; hydrocarbon production; ground deformation; Tengiz 


\section{Abstract}

Changes in subsurface pore pressures and stresses due to the extraction of hydrocarbons often cause deformation over oil and gas fields. This can have significant consequences, including ground subsidence, induced seismicity and well failures. Geodynamic monitoring is an important requirement in recognising potential threats in sufficient time for remedial measures to be implemented. Differential interferometric synthetic aperture radar (DInSAR) is increasingly utilised for monitoring ground deformation over oil and gas reservoirs, achieving greater spatial coverage than traditional field-based surveying techniques. However, ground deformation over oil and gas fields can extend regionally into the surrounding rural landscape, where many conventional DInSAR techniques are of limited use due to the dynamic nature of the land cover. The Intermittent Small Baseline Subset (ISBAS) method is an advanced DInSAR technique, which considers the intermittent nature of coherence over dynamic land cover types to obtain markedly more ground motion measurements in non-urban regions. In this study, the ISBAS technique is used to delineate deformation over the super-giant Tengiz oil field in rural Kazakhstan. Analysis of ENVISAT data for 2004-2009 reveals a well-defined bowl subsiding with a maximum rate of $-15.7 \mathrm{~mm} / \mathrm{year}$, corroborated by independent DInSAR studies and traditional levelling data. Subsequent application of ISBAS to Sentinel-1 data reveals significant evolution of deformation over the field in 2016-2017, with subsidence increasing dramatically to a maximum of $-79.3 \mathrm{~mm} / \mathrm{year}$. The increased density of measurements obtained using the ISBAS technique enables accurate and comprehensive delineation and characterisation of ground deformation in this rural landscape, without the need for corner reflectors. This enhanced information could ultimately aid reservoir characterisation and management, and improve understanding of the risk posed by ground subsidence and fault reactivation. 


\section{Introduction}

The extraction of oil and gas alters the geodynamic state of the environment by perturbing subsurface pore pressure and stresses, causing reservoirs to compact and the surface to deform (Chen, 2012). Deformation over oil and gas fields can have adverse consequences on the environment, infrastructure, the local population and economy, through ground subsidence (Fielding et al., 1998), induced seismicity (Yerkes and Castle, 1976) and well failures (Nagel, 2001). Active monitoring is therefore crucial in recognising potential threats posed by production activities before it is too late for remedial measures to be implemented.

In Kazakhstan, geodynamic monitoring is mandatory for assessing deformation and seismic hazards over oil and gas fields in the Caspian region (Kyrgizbayeva et al., 2015). This incorporates several traditional ground-based methods, including: gravimetric surveys to monitor reservoir compaction; GPS and precise levelling surveys to map ground deformation; and seismological surveys to monitor the frequency and distribution of natural and anthropogenically-induced seismicity. Monitoring is performed via deployment of a sensor network across the field and through repeat surveys at select locations (Kouznetsov et al., 1994).

Depending on the size of the reservoir, overlying geology and production volumes, ground deformation can extend over large areas to beyond the confines of the field itself (Baú et al., 1999). Accordingly, over reservoirs such as the super-giant Tengiz oil field in Kazakhstan, regional deformation monitoring is a necessity. However, traditional groundbased techniques are impractical and costly for providing such coverage in sufficient detail. A potential time- and cost-effective solution to regional ground deformation monitoring is satellite-based differential interferometric synthetic aperture radar (DInSAR). This technique determines sub-centimetre rates of ground displacement across large areas by computing the 
phase differences between SAR images acquired at two different time points (Rosen et al., 2000).

Numerous DInSAR algorithms exist to support ground displacement monitoring, and can be broadly grouped into two main categories (Hooper et al., 2012): Persistent Scatterers (e.g., Ferretti et al., 2001); and coherent scatterers, the most common being the Small Baseline Subset (SBAS) method (e.g., Berardino et al., 2002). Persistent Scatterers Interferometry (PSI) measures displacement of point-based targets whose scattering characteristics remain constant in the sequence of radar observations, whereas SBAS focuses on measuring the displacement of an area of ground containing a distribution of coherent scatterers. The PSI approach is most effective for monitoring localised deformation associated with point-wise structures, whereas SBAS is considered more suitable for regional deformation monitoring over rural areas (Caló et al., 2017). However, like PSI, SBAS is most effective over sites exhibiting high reflectivity and coherence in all radar images, as is common in urban and rocky areas (Lanari et al, 2007). Over more dynamic non-urban (i.e., vegetated) land cover types, SBAS typically provides only sparse coverage and fails to provide a detailed perspective of regional ground deformation processes (Bateson et al., 2015).

A potential solution is the Intermittent Small Baseline Subset (ISBAS) method (Sowter et al., 2013; Bateson et al., 2015), which is a modification of the SBAS algorithm (Berardino et al., 2002). The modification considers the intermittent nature of coherence over dynamic land cover (e.g., grassland, forests, agricultural fields), greatly increasing the density of measurements in non-urban areas to provide more ubiquitous coverage. The ISBAS method has previously been used to delineate and quantify surface motion due to groundwater abstraction (Sowter et al., 2016), underground coal mining (Bateson et al., 2015; Gee et al., 2017), landslides (Novellino et al., 2017) and peatland condition (Alshammari et al., 2018). The technique has also been applied over gas fields in the Alkmaar region of the Netherlands, 
where it was successfully validated against traditional levelling data (Gee et al., 2016). That study presented a valuable validation opportunity, given that suitable ground-truth data for nonurban locations is often scarce. However, the broader application of the ISBAS technique for wide-area monitoring of oil and gas operations in parts of the world with different environmental and climatic conditions has yet to be demonstrated.

The Tengiz oil field, with its dynamic semi-arid landscape and lack of built-up areas, represent a type of locality for which comprehensive ground deformation monitoring might be problematic using some DInSAR techniques. Nevertheless, with hydrocarbon production being the single dominant driver of ground deformation and a general paucity of dense vegetation cover, the oil field has been previously investigated using several DInSAR techniques, such as SBAS (Zhantaev et al., 2012) and SqueeSAR (Comola et al., 2016), therefore making it an excellent case study area. Accordingly, this study aims to assess the efficacy of the ISBAS technique for providing a detailed, comprehensive characterisation of deformation over the Tengiz field. Firstly, ground motion measurements obtained using ISBAS are verified through comparison with those for a conventional SBAS technique, the results of the previous DInSAR studies and data from a levelling survey. The ISBAS technique is then applied to contemporary SAR data to provide a new perspective of recent deformation over the oil field, demonstrating its potential to support geodynamic monitoring in the region.

\section{Study Area}

The Tengiz oil field is located approximately $150 \mathrm{~km}$ south-east of the city of Atyrau in western Kazakhstan and extends over $400 \mathrm{~km}^{2}$ (Figure 1). It is one of largest world-class oil fields of the Pre-Caspian Basin and is an isolated carbonate atoll formed through a build-up of shallow-water sedimentary sequences. The reservoir is estimated to contain up to 25 billion 
barrels of oil (of which 6-9 billion barrels are recoverable) and is at a depth of 3885-5117 m, making it the deepest super-giant reservoir in the world. The study area comprises $1,700 \mathrm{~km}^{2}$, encompassing the oil field and its immediate surroundings.

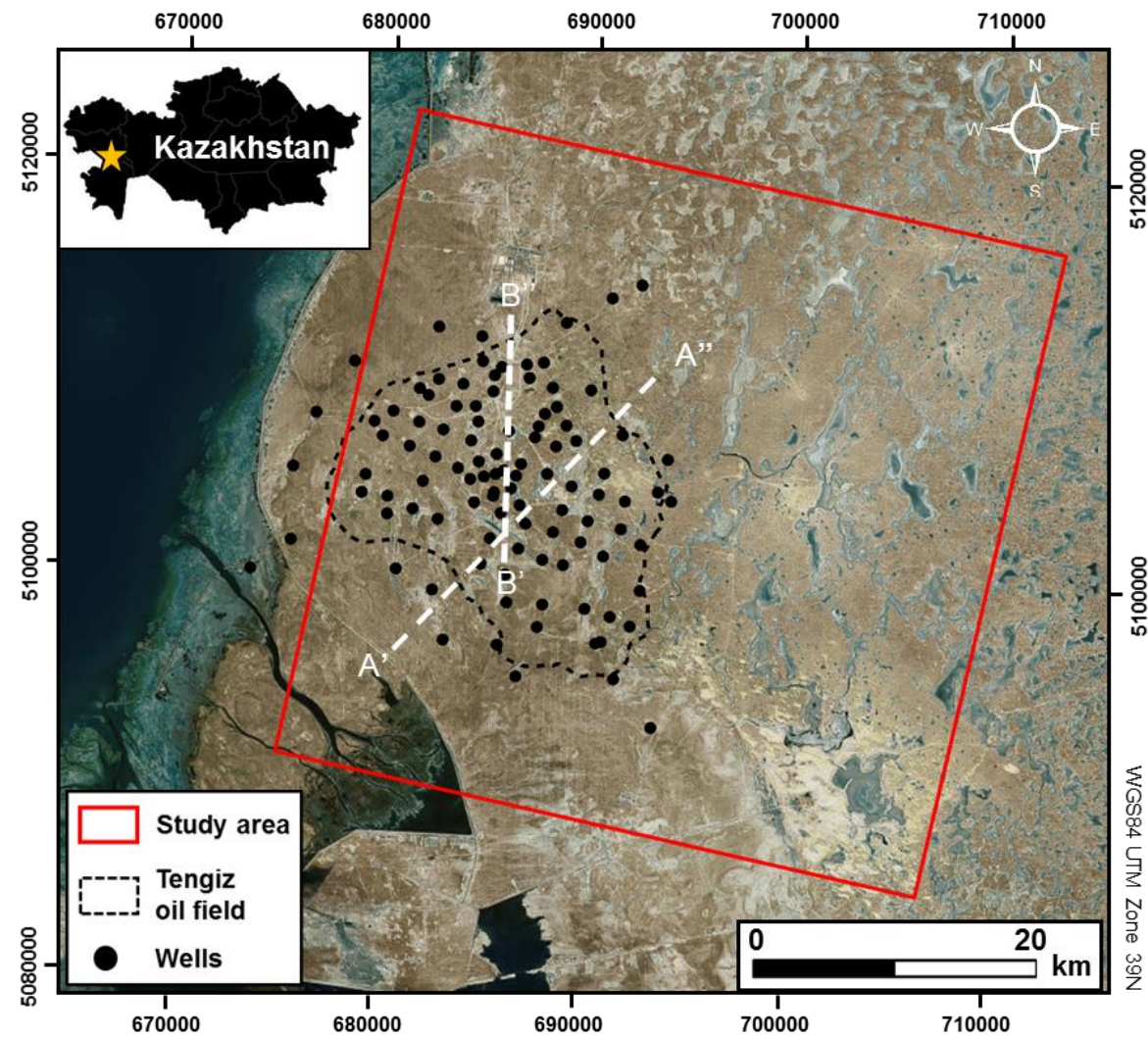

Figure 1. Location of the Tengiz oil field study area. Dashed white lines A'-A' and B'-B'" indicate the location of the geological cross-section shown in Figure 3 and levelling profile in Figure 8, respectively.

\subsection{Production history}

The Tengiz oil field was discovered in November 1979 by Ministry of Oil Industry of the Soviet Union via a 4095 m deep discovery well (Weber et al., 2003). Following extensive exploration between 1976 and the early-1980s, the 'Tengizneftegaz' production association was established in 1985 to develop the field. Construction of the Tengiz Oil and Gas Complex Facility Processing Plant commenced in early 1986 and was operational on $6^{\text {th }}$ April 1991, marking the start of commercial production activities at the site. Since 1993, Tengizchevroil, a 
joint enterprise between the Republic of Kazakhstan and Chevron Corporation, has been responsible for exploration and development of the oil field. Modernisation of the processing complex in 1997 boosted annual oil production to 50 million barrels (MMBL), while several concurrent projects further increased the production capacity to more than 91 MMBL by 2001 (Figure 2). By the end of 2005, the total number of wells drilled into the Tengiz reservoir was in excess of 115 (Collins et al., 2006). The Sour Gas Injection / Second Generation Plant expansion project was completed in 2008 , almost doubling the production capacity within a three-year period.

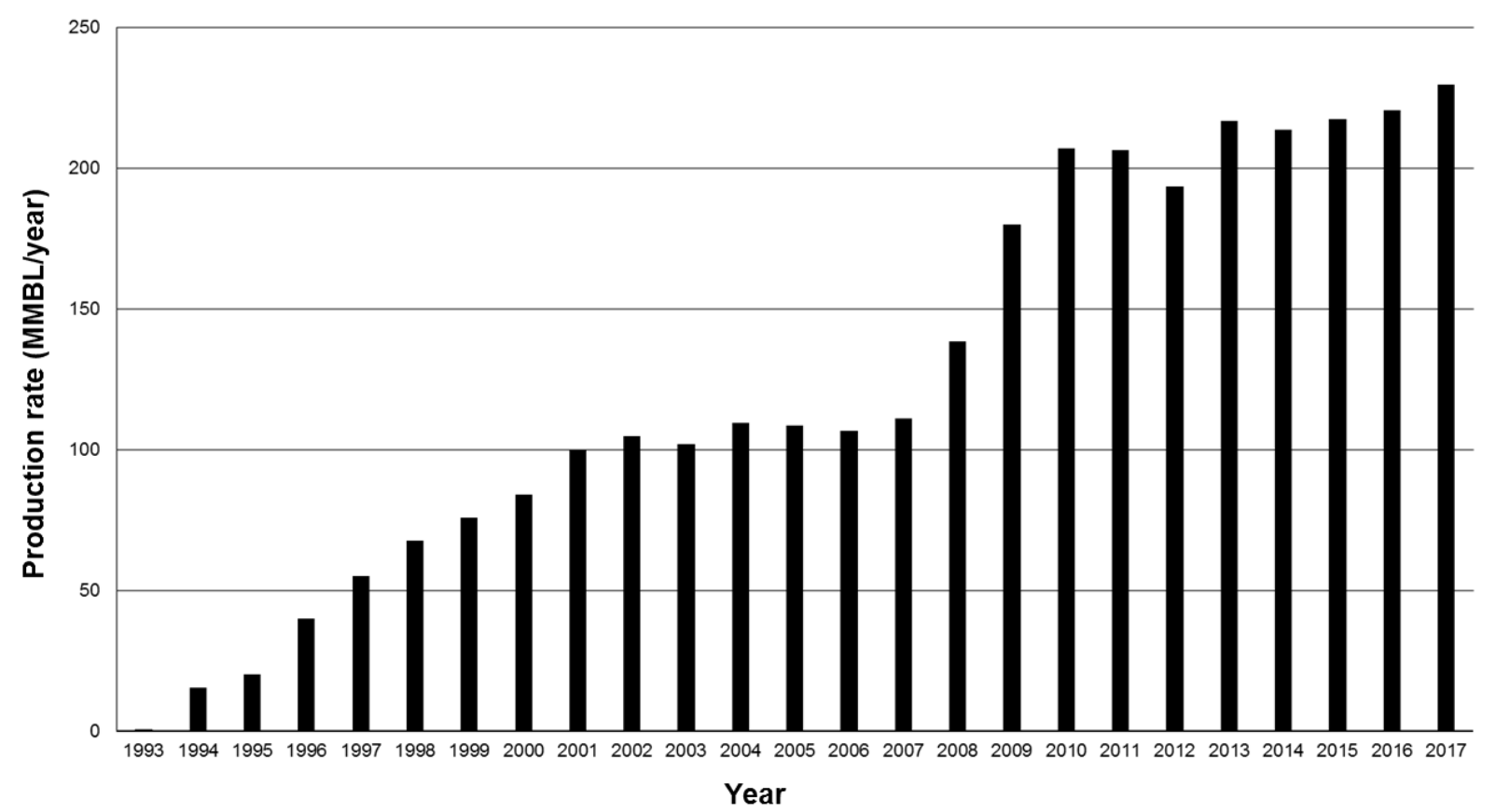

Figure 2. Tengizchevroil oil production rates during 1993-2017 in million barrels per year (MMBL/year).

\subsection{Geology and land cover}

Oil is produced from an isolated Devonian and Carboniferous carbonate build-up in the southeastern Pre-Caspian Basin. The steep-sided build-up formed through aggradation of a succession of platforms of late Famennian to early Bashkirian age (Figure 3), followed by 
Serpukhovian progradation and encasement in a thick layer of Kungurian salts (Collins et al., 2006). Historically, the field is segmented into three regions based on structural relief across the field: platform, rim and flank (Collins et al., 2013). The majority of production wells are situated on the platform, targeting hydrocarbons in grainstone and packstone lithofacies of the Upper Visean, Serpukhovian and Bashkirian reservoirs (Weber et al., 2003). Fewer wells have been drilled in the predominantly microbial boundstone and breccia that compose the flank regions.

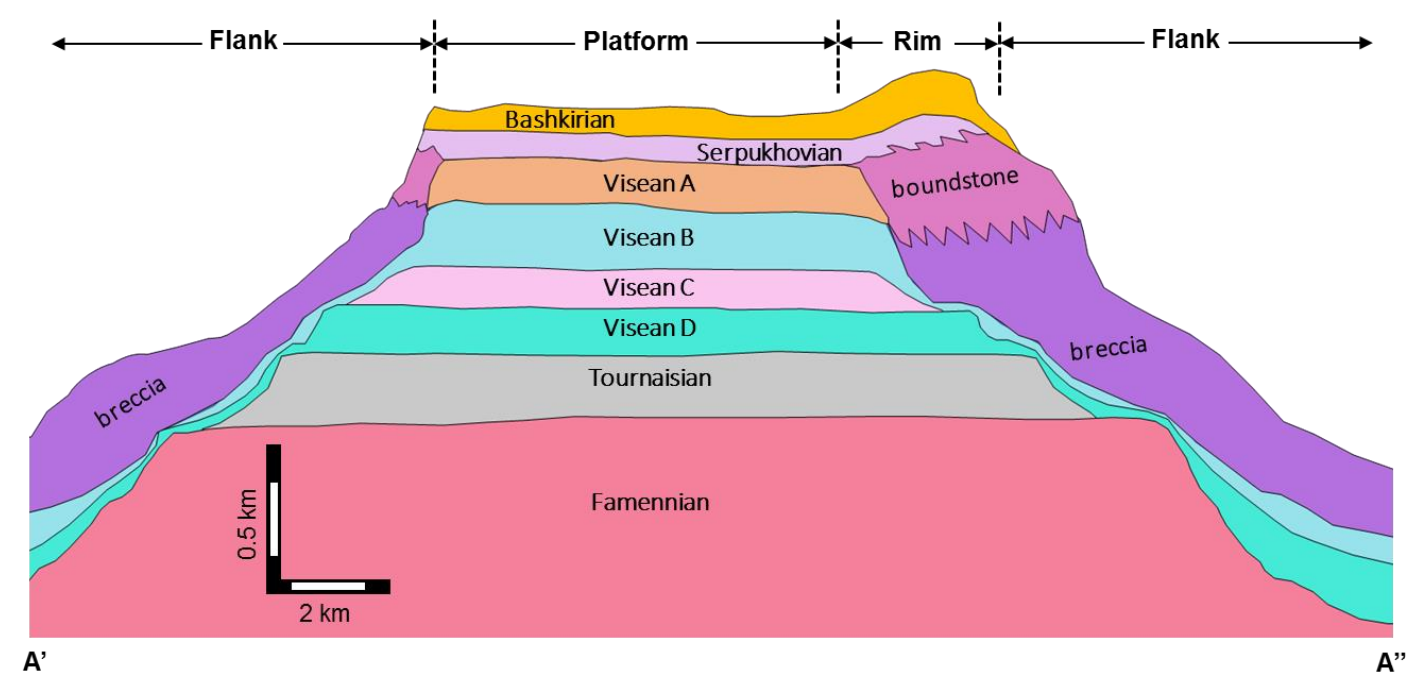

Figure 3. A southwest-northeast geological cross-section across the Tengiz oil field (profile A'-A' 'in Figure 1). Modified after Collins et al. (2006).

The region has a semi-arid climate with temperatures of up to $40^{\circ} \mathrm{C}$ in summer and $30^{\circ} \mathrm{C}$ in winter, and an average annual precipitation of 100-200 $\mathrm{mm}$ (Klein et al., 2012). The study area has low topographic relief, although the landscape is heavily pitted and dissected with depressions and channels that accumulate water seasonally as a result of snow melt and heavy precipitation. This subsequently evaporates to form mud and salt flats, producing a landscape dominated by a surficial covering of solonchak-type (saline) soils and a thin humic horizon. Vegetation is typically semi-arid, largely comprising ubiquitous shrubs and scrub of up to $0.5 \mathrm{~m}$ in height and of varying degrees of density. Common vegetation types found in 
developed areas of the field include Pegamum harmala (wild rue), Alhagi pseudalhagi (camelthorn), Batis maritima (saltwort) and Ceratocarpus (Japan International Cooperation Agency, 2007).

\section{Methodology}

\subsection{DInSAR analysis}

Thirty three descending SAR images acquired between $21^{\text {st }}$ July 2004 and $25^{\text {th }}$ February 2009 were used to compute the average vertical surface deformation over the study area for the time period. The images were acquired by the $\mathrm{C}$-band $(5.6 \mathrm{~cm}$ wavelength, $5.3 \mathrm{GHz}$ frequency) Advanced Synthetic Aperture Radar (ASAR) instrument on-board the European Space Agency's ENVISAT satellite. The complete ENVISAT ASAR image stack, which covers an area of approximately $100 \mathrm{~km} \times 100 \mathrm{~km}$ with a ground spatial resolution of $25 \mathrm{~m}$ in range and $5 \mathrm{~m}$ in azimuth, was clipped to a $42 \mathrm{~km} \times 40 \mathrm{~km}$ subset enclosing the study area (Figure 1) and then processed using DInSAR techniques.

Prior to processing, images were co-registered with sub-pixel precision to the master scene acquired on $16^{\text {th }}$ February 2005 . Multi-looking factors of 4 in range and 20 in azimuth were applied to reduce noise and increase coherence, producing pixels corresponding to a ground resolution of approximately $100 \mathrm{~m} \times 100 \mathrm{~m}$. As is common for ENVISAT small baseline surveys, interferograms were generated with a 4-year limit on the temporal baseline and $250 \mathrm{~m}$ on the perpendicular baseline, producing a set of 135 multi-looked differential interferograms. These restrictions minimise temporal and spatial decorrelation in the interferograms, therefore enhancing the phase quality and coherence (Gee et al., 2017), whilst reducing the impact of errors in the digital elevation model used to generate the differential interferograms. 
A standard coherent scatterer analysis was implemented on the multi-looked data by following the basic procedure described in Lanari et al. (2007), such that only pixels with an average coherence of $\geq 0.25$ across every interferogram were processed. Herein, this approach will be referred to as the SBAS technique. In contrast, the ISBAS technique identifies suitable pixels for analysis by incorporating a minimum quality standard alongside the coherence (Sowter et al., 2013). Specifically, a pixel is retained if it has a coherence of $\geq 0.25$ in a minimum number of interferograms, in doing so permitting the analysis of features that are intermittently coherent in the image stack. The minimum number of interferograms threshold allows a trade-off between the spatial coverage and accuracy of the derived deformation measurements, with a higher number of interferograms leading to a more accurate result with a sparser distribution of measurements. The optimum threshold can be identified from the empirical relationship between the standard error of the ISBAS velocity solutions and the number of interferograms (Cigna and Sowter, 2017). In this case, the minimum number of interferograms for the ISBAS technique was set as 60 .

Topographic phase was removed from the differential interferograms with the aid of the $90 \mathrm{~m}$ Shuttle Radar Topography Mission (SRTM) digital elevation model (Farr et al., 2007), as were any orbital ramps, before a statistical-cost network-flow algorithm was used to unwrap the coherent (i.e., SBAS) and intermittently coherent (i.e., ISBAS) pixels (Chen and Zebker, 2001). An average rate of motion for each pixel was then computed relative to a reference point, which was carefully chosen to ensure that it remained coherent in all interferograms and stable throughout the period of the DInSAR analysis. The reference point is located on a built structure within the confines of the oil and gas processing plant at $53.4^{\circ} \mathrm{N}, 46.2^{\circ} \mathrm{E}$. Finally, in the absence of sufficient ENVISAT data from an ascending orbit for stereo analysis, the average velocities in the radar line-of-sight (LOS) were converted to effective vertical velocities by dividing by the cosine of the angle of incidence for each pixel. This conversion 
was performed to enable comparison with both the levelling data and more recent SAR-derived deformation. Through convention, positive effective vertical velocities represent surface uplift (or heave) whereas negative velocities indicate ground subsidence.

The above ISBAS procedure was also applied to Sentinel-1 SAR data for 52 ascending images acquired between $11^{\text {th }}$ November 2016 and $29^{\text {th }}$ September 2017, in order to delineate recent ground deformation over the Tengiz field. Sentinel-1 is a two-satellite imaging radar mission carrying a C-Band (5.405 GHz) SAR instrument. Sentinel-1a and Sentinel-1b were launched in April 2014 and April 2016, respectively, and the two satellites currently maintain a conflict-free repeat pass of up to 6 days. A 1-year temporal baseline and $150 \mathrm{~m}$ perpendicular baseline resulted in 1179 multi-looked differential interferograms. The minimum number of interferograms threshold was set to 430. Again, due to insufficient Sentinel-1 descending orbit images for the same time period, the LOS measurements were converted to vertical velocities using a cosine correction, in order to normalise the different geometries between Sentinel-1 and ENVISAT for subsequent comparison.

\subsection{Levelling survey}

High-precision levelling is undertaken as part of the geodynamic monitoring programme over the Tengiz field. Levelling is performed relative to stable benchmarks designed for detecting anthropogenic surface deformation and displacements over active faults in the region. Available repeat levelling measurements overlapping with the period covered by the ENVISAT DInSAR analysis are from a north-south profile across the centre of the reservoir (Figure 1). The profile consists of 25 levelling benchmarks surveyed with an accuracy of \pm 0.4 mm using a Leica WILD NA3003 precision level (Nurpeisova et al., 2015). Repeat levelling was used to calculate the average rate of vertical displacement along the profile between 2001 and 2005. Although limited in quantity and only partially concurrent in terms of temporal 
coverage, these data do provide a valuable, independent means of authenticating DInSARderived ground deformation measurements. To achieve this, each levelling measurement is compared with its coincident ENVISAT ISBAS measurement, whilst realising the differences between the discrete point-based levelling measurements and areal $(100 \mathrm{~m} \times 100 \mathrm{~m}) \mathrm{DInSAR}$ measurements. A comparison must therefore be made under the assumption that the pointbased levelling velocities are representative of their wider surroundings (Gee et al., 2016).
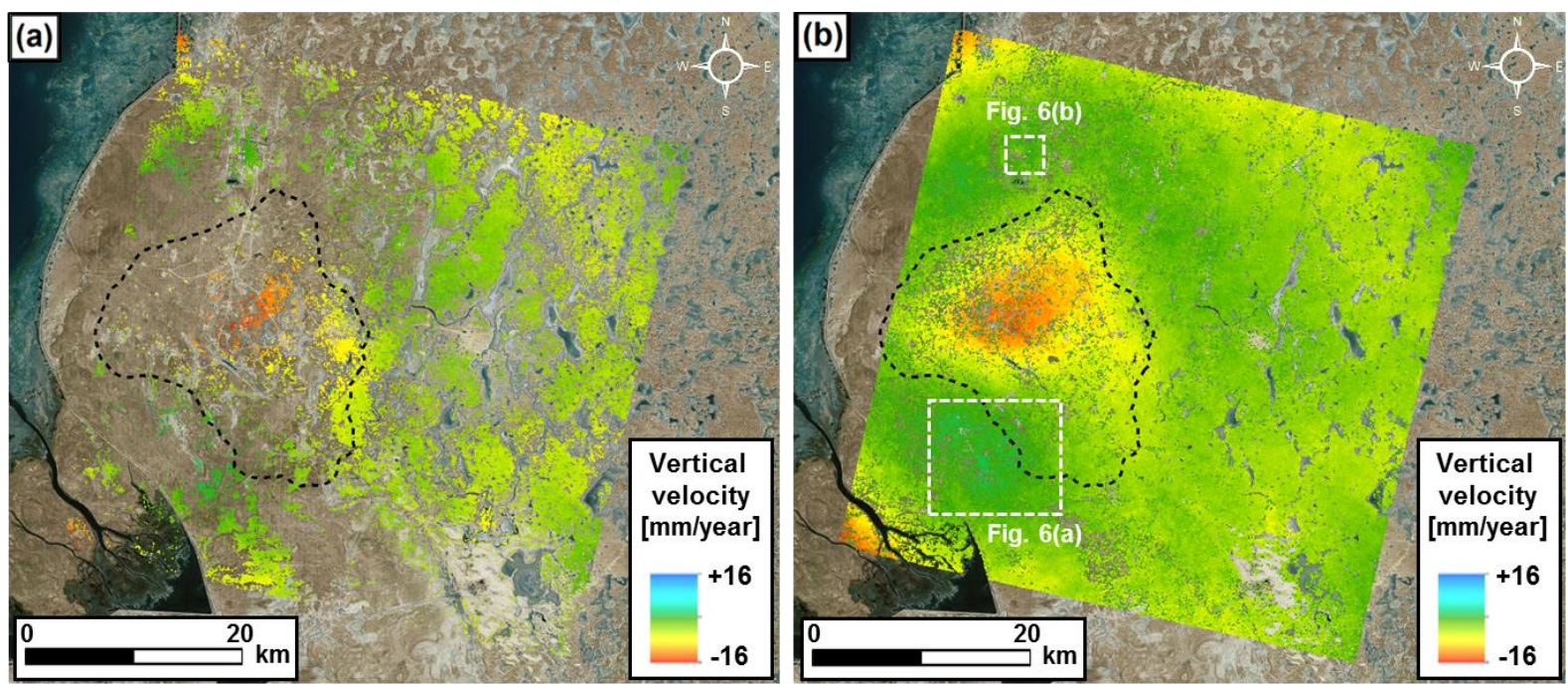

Figure 4. Ground deformation maps showing vertical velocities computed from ENVISAT data (2004-2009) using the (a) SBAS and (b) ISBAS technique. Positive velocities indicate uplift and negative velocities indicate subsidence. Dashed black line represents extent of the platform and rim region of the Tengiz oil field. Locations of Figure 6(a) and (b) are shown.

\section{Results and discussion}

\subsection{Verification of the ISBAS algorithm}

\subsubsection{Comparison of ENVISAT DInSAR coverage and spatial patterns of deformation}

Average vertical velocity ground measurements computed from ENVISAT data (20042009) using the SBAS and ISBAS techniques are shown in Figure 4. A total of 102,398 coherent pixels were identified using the SBAS technique, equating to an average of $\sim 60$ measurements $/ \mathrm{km}^{2}$. Coherent pixels tend to cluster around areas dominated by stable scatterers, 
such as the Tengiz Oil and Gas Complex just north of the platform boundary, and over blocks of less dissected ground in the centre and east of the study area (Figure 4a). Including pixels that exhibit intermittent coherence in the analysis markedly increases the spatial coverage and density of ground motion measurements (Figure 4b). At 366,842 pixels, the number of ISBAS ground motion measurements is 3.6-times greater than for SBAS, equating to an average of $\sim 215$ measurements $/ \mathrm{km}^{2}$. Overall, the ISBAS results cover $77 \%$ of the study area (in terms of total number of pixels) compared to just $\sim 22 \%$ coverage provided by SBAS. The additional measurements are situated across land cover types that are typically unfavourable for conventional DInSAR analysis; notably locations with dense scrubby vegetation cover. Such areas are often dynamic between observations due to physiological changes in the vegetation, and so will appear coherent in some interferograms but not in others (Sowter et al., 2013).

The SBAS results reveal predominantly stable ground, with the exception of a small area of subsidence near the centre of the field. The maximum subsidence rate is found to be $14 \mathrm{~mm} / \mathrm{year}$ over the northern portion of the platform. However, the enhanced coverage provided by the ISBAS technique better characterises the spatial pattern of deformation, revealing a more extensive area of subsidence that demarcates the extent of the reservoir. The ISBAS average and maximum vertical rate of subsidence over the platform and rim region is $5.5 \mathrm{~mm} /$ year and $-15.7 \mathrm{~mm} /$ year, respectively. As also indicated by the SBAS results, subsidence is greatest in the northern portion of the field, where the abundance of production wells and pore pressure perturbation is greatest (Dagistanova et al., 2011). Although not recognisable with SBAS, the ISBAS technique enables this deformation to be fully characterised as a subsidence bowl. This is in full agreement with the presence of a subsidence bowl previously computed through geomechanical modelling by Comola et al. (2016). Moreover, the subsidence rates are highly correlated with distinct pore pressure regions identified by Dagistanova et al. (2011), yielding a direct semi-quantitative insight into the 
geomechanical characteristics of the reservoir during this period (Figure 5). A weaker, secondary correlation with depth to the reservoir is also apparent (Collins et al., 2006), with associated changes in stresses being more readily transmitted to the surface through the thinner layers of overburden above the central and outer platform.

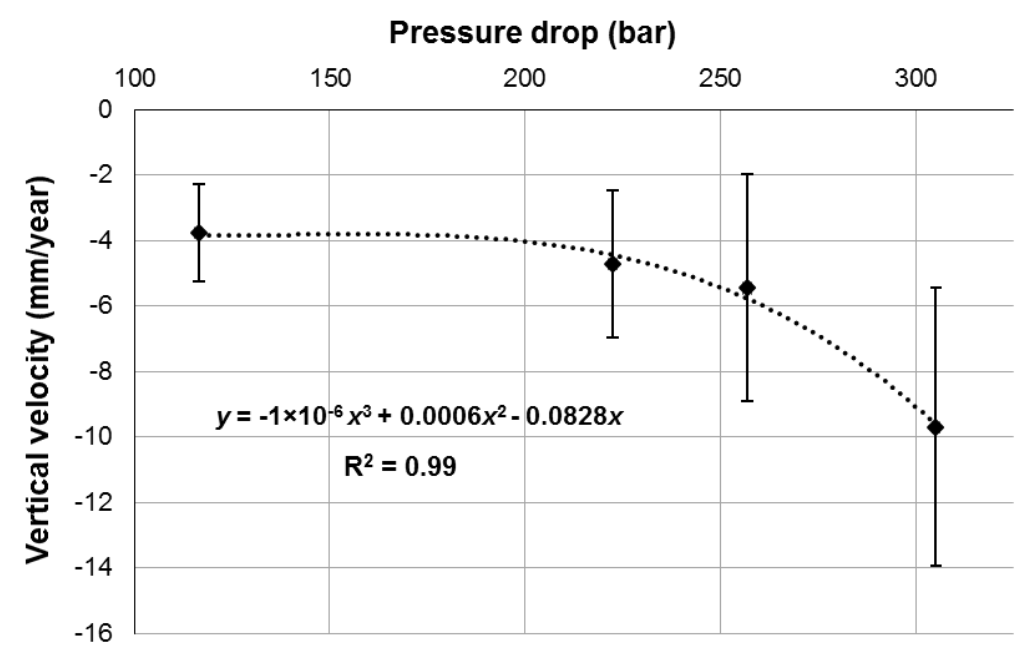

Figure 5. Correlation between pressure depletion (between 2009 and when first tapped) and mean ENVISAT ISBAS-derived subsidence rate within the pressure regions identified by Dagistanova et al. (2011). Error bars represent standard deviation of vertical velocities within the regions.

A number of previous DInSAR studies have been conducted in order to reveal deformation over the Tengiz oil field. When comparing these results to those obtained here, it is important to recognise that some disparity in the velocity magnitudes and measurement coverage is inevitable, even when the same technique is used, due to differences in the processing parameters (e.g., temporal and perpendicular baselines) and time-period covered by the data. Moreover, the use of a cosine correction to convert LOS measurements to effective vertical velocities imposes the assumption that the deformation field is entirely vertical in nature. Although this conversion approach was a necessity for the comparison with levelling data and Sentinel-1 results (as outlined in Section 3.1), this assumption may be not be strictly accurate, and so it is important to appreciate that the vertical velocities derived here are a limited approximation of the true land motion. 
Zhantaev et al. (2012) applied an SBAS analysis to ENVISAT ASAR and ALOS Phased Array L-band Synthetic Aperture Radar (PALSAR) data acquired for the periods 20042009 and 2007-2010, respectively. Both results show a deformation pattern consistent with the ISBAS result, dominated by the subsidence bowl over the northern portion of the field with a maximum rate of ground motion of up to $-20 \mathrm{~mm} / \mathrm{year}$ in the radar LOS. In terms of coverage, the ALOS SBAS result of Zhantaev et al. (2012) provides more ground motion measurements than the ENVISAT SBAS result present here, which is likely because more coherent pixels were identified given that the longer wavelength ALOS signal (L-band, $23.6 \mathrm{~cm}$ ) is less sensitive to temporal changes in surface conditions (Wempen and McCarter, 2017). However, notably, the ALOS SBAS result of Zhantaev et al. (2012) visually appears to provide significantly fewer measurements across the study area than obtained for the ISBAS approach applied to ENVISAT C-band data. Although in vegetated areas L-band data permits coherent phase recovery over longer temporal baselines compared to C-band, coherence can still decrease to $<0.25$ for time intervals of less than one year (Wei and Sandwell, 2010). Therefore, without applying a minimum temporal baseline to ALOS SBAS analysis, it is conceivable that some temporal decorrelation will inevitably occur over vegetated parts of the oil field. Consequently, pixels exhibiting any degree of temporal decorrelation will be immediately discarded in the ALOS SBAS analysis, whereas intermittently coherent pixels are retained in the ISBAS analysis, accounting for the additional ground motion measurements observed here despite utilising C-band data.

Comola et al. (2016) also processed ENVISAT data for 2004-2007 to ascertain parameters for optimising their geomechnical modelling. The data were processed using the SqueeSAR technique (Ferretti et al., 2011), which utilises both persistent and distributed scatterers in order to enhance the density of ground motion measurements in non-urban areas. The SqueeSAR outcome further verifies the ISBAS result by revealing a well-defined 
subsidence bowl over the reservoir with radar LOS displacement rates of up to $-20 \mathrm{~mm} /$ year, which is assumed to be almost entirely vertical given the small angle of incidence. Comola et al. (2016) also report strong west-east components $(8-10 \mathrm{~mm} / \mathrm{year})$ in the ground displacement field, however, it is not possible to verify this in the present study owing to the lack of sufficient data from an ascending orbit for 2004-2009. Visually, the SqueeSAR technique provides comparable coverage of the reservoir to that of ISBAS, while the reported average densities for persistent and distributed scatterers are 33 measurements $/ \mathrm{km}^{2}$ and 50 measurements $/ \mathrm{km}^{2}$, respectively, resulting in $\sim 150,000$ measurements (Comola et al., 2016). Although the density of measurements might appear lower than obtained using ISBAS, a comparison is inappropriate because of inherent differences between the two techniques (i.e., data type - points vs. pixels) and the ENVISAT scene extent and time period.
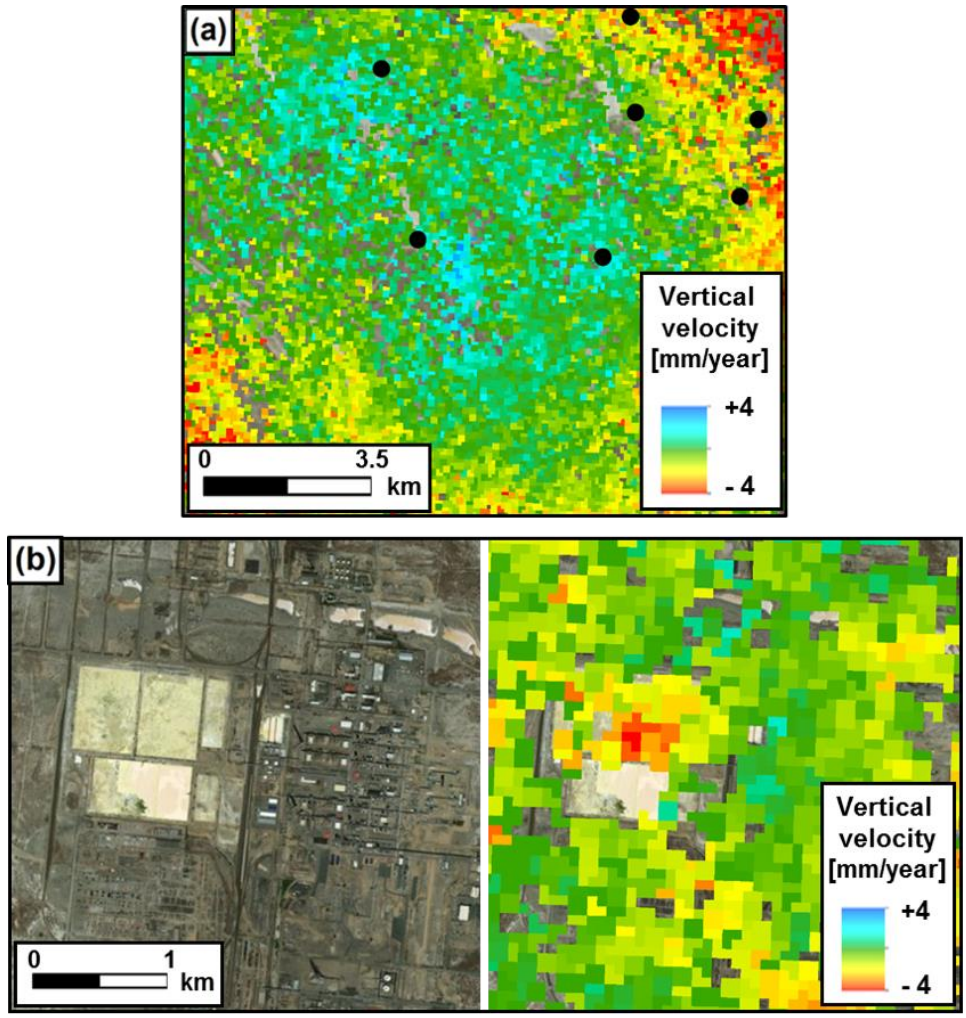

Figure 6. Localised deformation revealed by the ISBAS technique applied to ENVISAT. (a) Area of stability and uplift observed of the southeastern flank of the Tengiz oil field and (b) subsidence over the sulphur pads. Black circles represent well locations. 
The enhanced coverage provided by ISBAS resolves other interesting deformation features not previously referenced. A notable example lies to the southwest of the field, where an area of stability interlaced with localised patches of subtle uplift $(<3.5 \mathrm{~mm} / \mathrm{year})$ is observed (Figure 6a). This area overlies the flank of the reservoir, which, unlike the platform and rim regions, was observed to have undergone an unsystematic decline in pressure during the latter half of the time period covered by the DInSAR analysis (Collins et al., 2013). In fact, wells in this region were reported to have experienced either no change or a small increase in pore pressure during this time (Dagistanova et al., 2011), which would likely account for the observed deformation. Additionally, a small area of subsidence is observed over the sulphur pads at the oil and gas processing plant (Figure $6 \mathrm{~b}$ ). Sulphur is produced as a by-product of the refining process, and the motion is indicative of steady reduction in the height of the stockpile either through settlement or as a result of action to remove all reserves from the site during 2007-2015. The lack of velocity measurements over the pad directly south of the subsidence arises because of prolonged loss of coherence due to rapid changes in the scattering characteristics of the pad over time - most probably due to rapid removal of significant amounts of stockpiled material.

Table 1. Direct statistical comparison between levelling (2001-2005) and ENVISAT ISBAS (2004-2009) subsidence rates.

\begin{tabular}{lccccc}
\hline $\begin{array}{l}\text { Measurement } \\
\text { type }\end{array}$ & $\begin{array}{c}\text { Minimum } \\
\text { (mm/year) }\end{array}$ & $\begin{array}{c}\text { Maximum } \\
(\mathbf{m m} / \mathbf{y e a r})\end{array}$ & $\begin{array}{c}\text { Mean } \\
(\mathbf{m m} / \mathbf{y e a r})\end{array}$ & $\begin{array}{c}\text { Median } \\
(\mathbf{m m} / \mathbf{y e a r})\end{array}$ & $\begin{array}{c}\text { Standard } \\
\text { deviation } \\
(\mathbf{m m} / \text { year })\end{array}$ \\
\hline Levelling & -1.0 & -9.9 & -6.1 & -6.1 & 2.1 \\
ISBAS & -2.7 & -13.7 & -8.7 & -9.8 & 3.6 \\
& & & & \\
Number of measurements $=25$ & & & & \\
Mean absolute error = 2.71 mm/year \\
RMSE = 3.18 mm/year
\end{tabular}




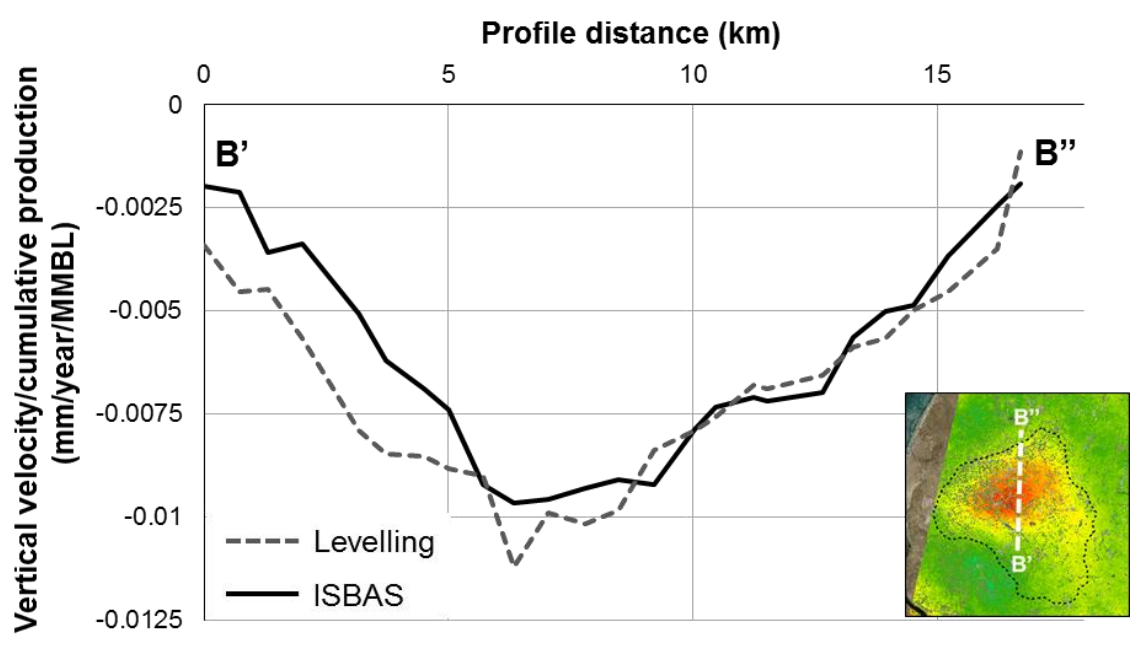

Figure 7. Comparison of production-normalised deformation rates across the Tengiz reservoir measured using levelling (for the period 2001-2005) and ISBAS (2004-2009). The location of the profile is indicated in the inset and Figure 1.

\subsubsection{Comparison with levelling data}

A direct comparison reveals a reasonable level of agreement between the high-precision levelling and ENVISAT ISBAS measurements, with a root-mean-square error (RMSE) of 3.18 $\mathrm{mm} /$ year and mean absolute error of $2.71 \mathrm{~mm} /$ year (Table 1). Measurements on the periphery of the reservoir show greater correspondence through an RMSE of $0.64 \mathrm{~mm} / \mathrm{year}$. Differences in the subsidence rate are largest towards to the centre of the reservoir, where the maximum rates are $-13.7 \mathrm{~mm} /$ year and $-9.9 \mathrm{~mm} /$ year for the ISBAS technique and levelling, respectively. This discrepancy is anticipated to be due primarily to the temporal offset between the two sets of measurements, meaning that they do not reflect the exact same field operating conditions. For instance, the levelling measurements cover the period 2001-2005 when oil production was relatively low and steady (see Figure 2), while the DInSAR analysis captures the substantial post-2007 rise in oil production that likely led to increased reservoir compaction and ground deformation. To account for this discrepancy, the two sets of ground motion measurements were normalised to cumulative production between 1993 and the end of each measurement period (i.e., cumulative production for 1993-2005 and 1993-2009 for the levelling and 
DInSAR data, respectively). This produces a higher level of correspondence between the deformation trends, clearly confirming the presence of a subsidence bowl over the reservoir (Figure 7). Moreover, it confirms that production rate is a primary control on the rate of deformation observed over the oil field. Any minor residual discrepancy between the two datasets will arise from the contribution of other factors, including the comparison between point-based and areal measurements, use of different reference points for measuring rates of surface displacement, LOS cosine correction, and other variations in the field operating conditions.
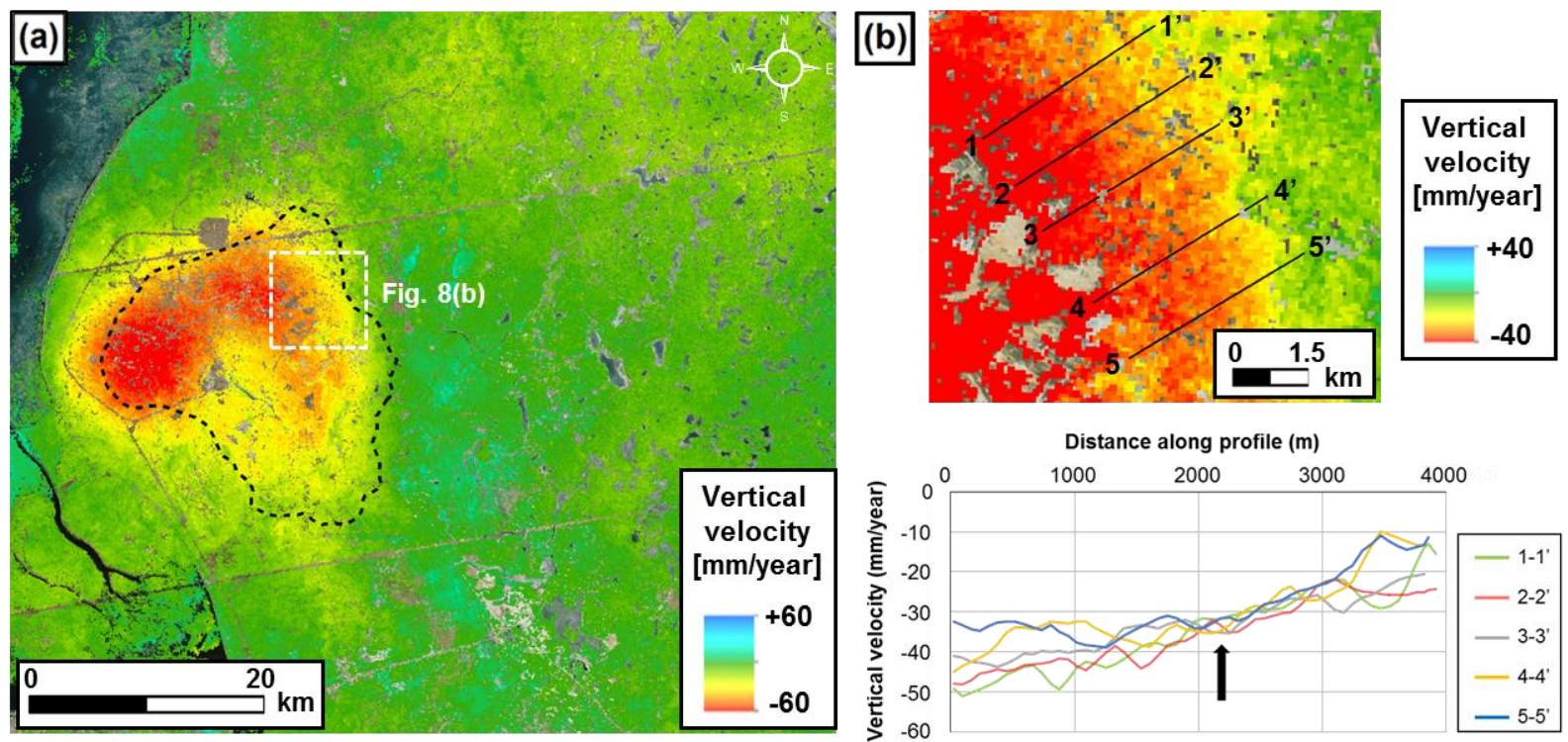

Figure 8. (a) Recent ground deformation map of the study area showing vertical velocities computed from Sentinel-1 data (2016-2017) using the ISBAS technique. (b) Zoomed subset of the deformation map and cross-sectional profiles at the eastern margin of the oil field. The black arrow indicates a potential break-of-slope in the subsidence rate.

\subsection{Recent ground deformation}

The ISBAS technique applied to Sentinel-1 data (2016-2017) provides a novel insight into recent ground deformation over the Tengiz field (Figure 8a). The deformation map - which extends beyond the ENVISAT analysis and covers $79 \%$ of the study area - illustrates that the previously recognised subsidence bowl has evolved into a broader region of subsidence that 
now spans the entirety of the reservoir. In fact, the subsidence has extended by up to $3 \mathrm{~km}$ beyond the denoted confines of the platform and rim region and into the flanks on all but the eastern side, which is seemingly bound by northwest-southeast trending faults at this margin (Anissimov et al., 2000). A potential, albeit subtle, northwest-southeast lineament formed by a break-of-slope in the rate of subsidence across strike is somehwhat apparent in this area (Figure $8 b)$.

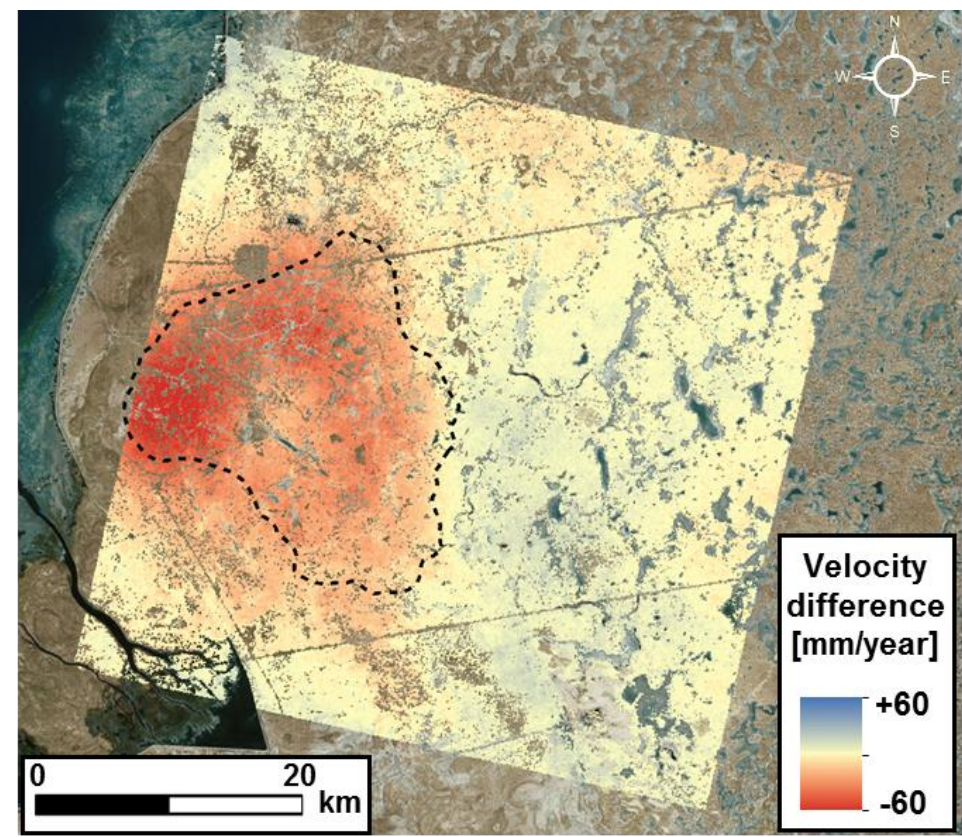

Figure 9. Difference in the rate of vertical ground deformation between the periods 2016-2017 (Sentinel-1) and 2004-2009 (ENVISAT). Negative velocity differences represent an increase in the rate of subsidence since 2004-2009.

The average and maximum rates of subsidence observed over the platform and rim region are $-36.1 \mathrm{~mm} /$ year and $-79.3 \mathrm{~mm} /$ year, respectively. This represents substantial 6.6-fold and 5-fold increases in subsidence compared to the 2004-2009 period. The greatest increases in subsidence rate are at the northern, eastern and western margins of the field (Figure 9), coinciding with zones of superpermeability (Anissimov et al., 2000). Such areas have been subject to recent field development due to their high fracture densities, making them the highest producing areas in recent years (Collins et al., 2014). Deformation in the north and west has 
accelerated most, with subsidence typically increasing by $50-60 \mathrm{~mm} /$ year with respect to the 2004-2009 rates. Subsidence rate over the central and southern portions has increased by approximately $50 \%$ of that over the north and west of the field (i.e., $20-30 \mathrm{~mm} / \mathrm{year}$ ). The centre of the platform is less fractured than the margins, although sour gas injection technology was utilised for enhanced oil recovery in this particular region in 2008. Based on the Sentinel1 ISBAS result, the net volume loss over the main platform and rim region for the period 20162017 alone is estimated at $5.61 \times 10^{6} \mathrm{~m}^{3} /$ year. Such volume loss and subsidence rates are expected to be associated with significant pressure depletion and compaction over the field this is presumably one of the key drivers behind the recent Future Growth Project-Wellhead Pressure Management Project that is designed to boost production across the field.

\subsection{Deformation monitoring outlook}

The present and previous studies clearly demonstrate that DInSAR has potential for monitoring deformation over the Tengiz oil field. Although the potential of the more conventional techniques (e.g., SBAS, PSI) is somewhat limited to built-up and barren areas, advanced techniques (e.g., ISBAS, SqueeSAR) are capable of extending monitoring into nonurban areas. This is advantageous over the Tengiz field since it has fairly ubiquitous, semi-arid vegetation cover, albeit with varying densities.

Some advantages of the ISBAS technique have previously been demonstrated over gas fields in the more temperate clime of the agricultural and woodland dominated rural landscape of Alkmaar (Gee et al., 2016), and this unique capability has been further strengthened by this study over a contrasting rural landscape. With the capability to obtain ground motion measurements over both urban and different rural land cover types, ISBAS can provide a more complete picture of the deformation over hydrocarbon reservoirs. Importantly, this remote sensing technique can provide more continuous and detailed deformation mapping over large 
areas for only a fraction of the time and cost of an equivalent ground-based survey, without sacrificing accuracy. This could have significant consequences for reservoir management, by helping to better optimise geomechanical models to enable the Tengiz reservoir geometry and pore pressure variation to be resolved with finer spatial detail (Comola et al., 2016). The costeffectiveness of DInSAR will only further increase now that national-scale DInSAR deformation mapping is possible (Sowter et al., 2018), subsequently enabling a single map to be used for a variety of different applications, e.g., the simultaneous monitoring of neighbouring Korolev oil field.

The typical poor coverage of conventional DInSAR methods over vegetated areas can be solved by placing a dense network of artificial scatterers (corner reflectors) across the landscape (Henschel et al, 2014; Rohmer et al, 2014). However, the density of measurements provided by the ISBAS method has the potential to make that solution redundant in most cases. This further compounds the efficacy of ISBAS as a readily deployable operational ground motion monitoring tool.

The prospect for continued operational monitoring of the Tengiz oil field using DInSAR has improved considerably with the launch of the Sentinel-1, which represents a significant improvement in reliability and revisit time over its SAR predecessors (Torres et al., 2012). Moreover, the near real-time data is provided both free and on an open access basis to all end-users. Here, Sentinel-1 helped reveal dramatic changes in both the spatial extent and rates of subsidence since 2004-2009. This clearly illustrates the ongoing need to monitor deformation over the oil field in order to assess the impact that it could have on the integrity of wells and infrastructure, such as the processing plant and pipelines. Additional high-resolution time-series data of ground motion obtained from Sentinel-1 would also be beneficial in this respect, particularly for evaluating the effectiveness of mitigation strategies designed to control reservoir compaction, subsidence and induced-seismicity. 


\section{Conclusion}

This study assesses the capability of the ISBAS DInSAR technique for monitoring ground deformation over the Tengiz oil field in Kazakhstan. Analysis of ENVISAT SAR data for a time period of 2004-2009 revealed a well-defined bowl subsiding with a maximum rate of $-15.7 \mathrm{~mm} /$ year, which is corroborated against other DInSAR studies and validated against levelling data. However, the improved coverage and density of accurate measurements obtained using the ISBAS technique enables a more comprehensive understanding of ground deformation patterns to be obtained. Importantly, this is achieved without the need for deploying corner reflectors and through use of an arbitrary reference point that does not require absolute ground-based positioning data, thus improving the practicality of monitoring. Application of the ISBAS method to Sentinel-1 data helped delineate recent deformation over the field, manifest as an increase in spatial extent of the subsidence bowl and a dramatic rise in subsidence to a maximum rate of $-79.3 \mathrm{~mm} /$ year. With continued monitoring a necessity, Sentinel-1 data used in conjunction with innovative DInSAR approaches, such as ISBAS, can offer a more cost- and time-effective operational means of regional, long-term deformation monitoring than a conventional ground-based sensor network. Ultimately, more detailed and comprehensive ground motion measurements could enable better reservoir characterisation and management, and a better understanding of the associated risk posed by ground subsidence and fault reactivation.

\section{Acknowledgements}

This research was supported by the GeoEnergy Research Centre (GERC) and Geomatic Ventures Limited. The authors are grateful to the reviewers for their comments, which were valuable for improving the quality of this manuscript. 


\section{References}

Alshammari, L., Large, D.J., Boyd, D.S., Sowter, A., Anderson, R., Andersen, R., and Marsh, S. (2018). Long-term peatland condition assessment via surface motion monitoring using the ISBAS DInSAR technique over the Flow Country, Scotland. Remote Sensing, 10, 1103.

Anissimov, L., Postnova, E., and Merkulov, O. (2000). Tengiz oilfield: geological model based on hydrodynamic data. Petroleum Geoscience, 6, 59-65.

Bateson, L., Cigna, F., Boon, D., and Sowter, A. (2015). The application of the intermittent SBAS (ISBAS) InSAR method to the south Wales coalfield, UK. International Journal of Applied Earth Observation and Geoinformation, 34, 249-257.

Baú, D., Gambolati, G., and Teatini, P. (1999). Residual land subsidence over depleted gas fields in the Northern Adriatic basin. Environmental and Engineering Geoscience, 4, 389-405.

Berardino, P., Fornaro, G., Lanari, R., Sansosti, E. (2002). A new algorithm for surface deformation monitoring based on small baseline differential SAR interferograms. IEEE Transactions on Geoscience and Remote Sensing, 40(11), 2375-2383.

Caló, F. Notti, D., Galve, J.P., Abdikan, S., Görüm, T., Pepe, A., and Şanli, F.B. (2017). DInSAR-based detection of land subsidence and correlation with groundwater depletion in Konya Plain, Turkey. Remote Sensing, 9(1), 83.

Chen, Z.R. (2012). Poroelastic model for induced stresses and deformations in hydrocarbon and geothermal reservoirs. Journal of Petroleum Science and Engineering, 80, 41-52.

Chen, C.W., and Zebker, H.A. (2001). Two-dimensional phase unwrapping with use of statistical models for cost functions in nonlinear optimization. Journal of the Optical Society of America A, 18, 338-351.

Cigna, F., and Sowter, A. (2017). The relationship between intermittent coherence and precision of ISBAS InSAR ground motion velocities: ERS-1/2 case studies in the UK. Remote Sensing of Environment, 202, 177-198. 
Collins, J.F., Kenter, J.A.M., Harris, P.M., Kuanysheva, G., Fischer, D.J., and Steffen, K.L. (2006). Facies and reservoir-quality variations in the late Visean to Bashkirian outer platform, rim, and flank of the Tengiz buildup, Precaspian Basin, Kazakhstan, in P.M. Harris and L.J. Weber (eds.), Giant hydrocarbon reservoirs of the world: From rocks to reservoir characterization and modelling (pp. 55-95). AAPG Memoir 88/SEPM Special Publication.

Collins, J., Narr, W., Harris, P.M., Playton, T., Jenkins, S., Tankersley, T., and Kenter, J.A.M. (2013). Lithofacies, depositional environments, burial diagenesis, and dynamic field behavior in a carboniferous slope reservoir, Tengiz Field (Republic of Kazakhstan), and comparison with outcrop analogs, in P.M. Harris and L.J. Weber (eds.), Deposits, architecture and controls of carbonate margin, slope and basinal settings (pp. 50-83). SEPM Special Publication 105.

Collins, J.F., Katz, D., Harris, P.M., and Narr, W. (2014). Burial cementation and dissolution in carboniferous slope facies, Tengiz field, Kazakhstan: evidence for hydrothermal activity, AAPG Annual Conference, Pittsburgh, USA, 19-22 May 2013, AAPG Search and Discovery Article \#20234.

Comola, F., Janna C., Lovison, A., Minini, M., Tamburini, A., and Teatini, P. (2016). Efficient global optimization of reservoir geomechanical parameters based on synthetic aperture radarderived ground displacements. Geophysics, 81(3), M23-M33.

Dagistanova, K., Aitzhanov, A., Belanger, D., Bateman, P., Camerlo, R., Fitzmorris, R., Hui, M., Jacobs, G., King, G., Laidlaw, C., Narr, W., Pan, Y., Peake, W., Shook, M., Skalinski, M., Sullivan, M., Tankersley, T., Tolessin, D., Yessaliyeva, A., and Zhumagulova, A. (2011). Integration of dynamic data into characterization of the Tengiz reservoir: Tengiz slope, AAPG European Region Annual Conference, Kiev, Ukraine, 17-19 October 2010, AAPG Search and Discovery Article \#50399.

Farr, T.G., Rosen, P.A., Caro, E., Crippen, R., Duren, R., Hensley, S., Kobrick, M., Paller, M., Rodriguez, E., Roth, L., Seal, D., Shaffer, S., Shimada, J., Umland, J., Werner, M., Oskin, M., Burbank, D., and Alsdorf, D. (2007). The shuttle radar topography mission. Reviews of Geophysics, 45(2), RG2004. 
Ferretti, A., Prati, C., and Rocca, F. (2001). Permanent scatterers in SAR interferometry. IEEE Transactions on Geoscience and Remote Sensing, 39(1), 8-20.

Ferretti, A., Fumagalli, A., Novali, F., Prati, C., Rocca, F., and Rucci, A. (2011). A new algorithm for processing interferometric data-stacks: SqueeSAR. IEEE Transactions on Geoscience and Remote Sensing, 49(9), 3460-3470.

Fielding, E.J., Blom, R.G., and Goldstein, R.M. (1998). Rapid subsidence over oil fields measured by SAR interferometry. Geophysical Research Letters, 25, 3215-3218.

Gee, D., Sowter, A., Novellino, A., Marsh, S., and Gluyas, J. (2016). Monitoring land motion due to natural gas extraction: validation of the Intermittent SBAS (ISBAS) DInSAR algorithm over gas fields of North Holland, the Netherlands. Marine and Petroleum Geology, 77, 13381354.

Gee, D., Bateson, L., Sowter, A., Grebby, S., Novellino, A., Cigna, F., Marsh, S., Banton, C. and Wyatt, L. (2017). Ground motion in areas of abandoned mining: application of the Intermittent SBAS (ISBAS) to the Northumberland and Durham Coalfield, UK Geosciences, $7(3), 85$.

Henschel, M.D., Shen, L., Shipman, T., Lehrbrass, B., and Aubé, G. (2014). Remote monitoring of SAGD operations with satellite based InSAR, Society of Petroleum Engineers Heavy Oil Conference, Calgary, Canada, 10-12 June 2014, SPE-170082-MS.

Hooper, A., Bekaert, D., Spaans, K., and Arıkan, M. (2012). Recent advances in SAR interferometry time series analysis for measuring crustal deformation. Tectonophysics, 514$517,1-13$.

Japan International Cooperation Agency. (2007). The study on capacity development on pollution prevention and control in the petroleum industry in the Caspian Sea and its coastal areas in the Republic of Kazakhstan: Final Report. Ministry of Environmental Protection, The Republic of Kazakhstan, pp. 55. 
Klein, I., Gessner, U., and Kuenzer, C. (2012). Regional land cover mapping and change detection in Central Asia using MODIS time-series. Applied Geography, 35, 219-234.

Kouznetsov, O., Sidorov, V., Katz, S., and Chilingarian, G. (1994). Interrelationships among seismic and short-term tectonic activity, oil and gas production, and gas migration to the surface. Journal of Petroleum Science and Engineering, 13, 57-63.

Kyrgizbayeva, G., Nurpeisova, M., and Sarybayev O. (2015). The monitoring of earth surface displacements during the subsurface development, in G. Pivnyak, V. Bondarenko and I. Kovalevska (eds.), New Developments in Mining Engineering: Theoretical and Practical Solutions of Mineral Resources Mining (pp. 161-167). Taylor \& Francis Group, London, UK.

Lanari, R., Casu, F., Manzo, M., Zeni, G., Berardino, P., Manunta, M., and Pepe, A. (2007). An overview of the small baseline subset algorithm: a DInSAR technique for surface deformation analysis. Pure and Applied Geophysics, 164, 637-661.

Nagel, N.B. (2001). Compaction and subsidence issues within the petroleum industry: from Wilmington to Ekofisk and beyond. Physics and Chemistry of the Earth, Part A: Solid Earth and Geodesy, 26(1-2), 3-14.

Novellino, A., Cigna, F., Sowter, A., Ramondini, M., and Calcaterra, D. (2017). Exploitation of the Intermittent SBAS (ISBAS) algorithm with COSMO-SkyMed data for landslide inventory mapping in north-western Sicily, Italy. Geomorphology, 280, 153-166.

Nurpeisova, M., Kyrgizbaeva, G.M., Sarybaev, O.A., and Aitkazinova, S.K. (2015). The Methodology of monitoring the earth surface displacements during the development of the subsoil. News of the National Academy of Sciences of the Republic of Kazakhstan, 4(412), 95100.

Rohmer, J., Loschetter, A., Raucoules, D., de Michele, M., Le Gallo, Y., and Raffard, D. (2014). Improving Persistent Scatterers Interferometry (PSI) analysis in highly vegetal/agricultural areas for long term $\mathrm{CO}_{2}$ storage monitoring. Energy Procedia, 63, 40194026. 
Rosen, P.A., Hensley, S., Joughin, I.R., Li, F.K., Madsen, S.N., Rodríguez, E., and Goldstein, R.M. (2000). Synthetic Aperture Radar Interferometry. Proceedings of the IEEE, 88(3), 333382.

Sowter, A., Bateson, L., Strange, P., Ambrose, K., and Syafiudin, M. (2013). DInSAR estimation of land motion using intermittent coherence with application to the South Derbyshire and Leicestershire coalfield. Remote Sensing Letters, 4(10), 979-987.

Sowter, A., Che Amat, M., Cigna, F., Marsh, S., Athab, A., and Alshammari, L. (2016). Mexico City land subsidence in 2014-2015 with Sentinel-1 IW TOPS: results using the Intermittent SBAS (ISBAS) technique. International Journal of Applied Earth Observation and Geoinformation, 52, 230-242.

Sowter, A., Athab, A., Novellino, A., Grebby, S., and Gee, D. (2018). Supporting energy regulation by monitoring land motion on a regional and national scale: A case study of Scotland. Proceedings of the Institution of Mechanical Engineers, Part A: Journal of Power and Energy, 232(1), 85-99.

Torres, R., Snoeij, P., Geudtner, D., Bibby, D., Davidson, M., Attema, E., Potin, P., Rommen, B., Floury, N., Brown, M., Traver, I.N., Deghaye, P., Duesmann, B., Rosich, B., Miranda, N., Bruno, C., L'Abbate, M., Croci, R., Pietropaolo, A., Huchler, M., and Rostan, F. (2012). GMES Sentinel-1 mission. Remote Sensing of Environment, 120, 9-24.

Weber, L.J., Francis, B.P., Harris, P.M., and Clark, M. (2003). Stratigraphy, lithofacies, and reservoir distribution, Tengiz Field, Kazakhstan, in W.M. Ahr, P.M. Harris, W.A. Morgan, and I.D. Somerville (eds.), Permo-carboniferous carbonate platforms and reefs (pp. 351-394). SEPM Special Publication 78 and AAPG Memoir 83.

Wei, M., and Sandwell, D.T. (2010). Decorrelation of L-band and C-band interferometry over vegetated areas in California. IEEE Transactions on Geoscience and Remote Sensing, 48(7), 2942-2952. 
Wempen, J.M., and McCarter, M.K. (2017). Comparison of L-band and X-band differential interferometric synthetic aperture radar for mine subsidence monitoring in central Utah. International Journal of Mining Science and Technology, 27, 159-163.

Yerkes, R.F., and Castle, R.O. (1976). Seismicity and faulting attributed to fluid extraction. Engineering Geology, 10(2-4), 151-167.

Zhantaev, J., Fremd, A., Ivanchukova, A., Kaldybayev, A., Nurakynov, S., Kantemirov, Y., and Nikiforov, S. (2012). Satellite radar monitoring of land surface subsidence over Tengiz oil and gas field. Geomatics Magazine, 1(14), 61-71. [In Russian] 